Editorial

\title{
A study on clinico-laboratory profile of newborns with perinatal asphyxia admitted to tertiary care hospital
}

\author{
U.M. Rao Kuppili ${ }^{1}$, Simhachalam M. ${ }^{2}$, Revathi M.S. ${ }^{3}$ \\ ${ }^{1}$ Dr. Uma Maheswara Rao Kuppili, Professor, ${ }^{2}$ Dr. Simhachalam Malluvalasa, Assistant Professor, ${ }^{3}$ Dr. Mudunuri Satya \\ Revathi, Post graduate, all authors are affiliated with Department of Paediatrics, ASRAM Medical College, Eluru, \\ Andhra Pradesh, India.
}

Corresponding Author: Dr. Simhachalam Malluvalasa, Assistant Professor, Department of Paediatrics, ASRAM Medical College, Eluru, Andhra Pradesh, India. Email: getmsc.doc@gmail.com

\begin{abstract}
Introduction: Asphyxia is the single most important cause of still-births accounting for $45.1 \%$ of all cases. Although many organ systems can be affected by hypoxia, it is the nervous system that bears the brunt of perinatal asphyxia in the long run. Once the cerebral injury has occurred, the management is mainly supportive. Newer cerebro protective therapies are being tried. The present study aims at correlating the Severity of asphyxia with the severity of HIE and also to assess the perinatal factors, clinico laboratory profile and immediate outcome in asphyxiated newborns. Materials and methods: It is a prospective, descriptive clinical study done at NICU, ASRAM medical college Eluru.92 newborn babies who fulfilled the selection criteria for perinatal asphyxia during the study period September 2015 to August 2017 formed the study group. The stage of encephalopathy was assessed according to Sarnat and Sarnat Clinical staging system. Perinatal asphyxia was graded as moderate or severe based on $\mathrm{pH}$ and/or Apgarscore. Chi square test and Fisher Exact test has been used to find the significant association of HIE staging and outcome and other study characteristics. Results: Among 92 asphyxiated newborns, Pregnancy was complicated by the presence of PIH in 15 (16.3\%), APH in 3 (3.3\%), MSAF was present in 51 (55.4\%), maternal anemia in $16(17.4 \%)$ and PROM in 9 (9.8\%). Labour was complicated by prolonged II stage in $12(13.0 \%)$ of them and cord prolapse was seen in $1(1.1 \%)$. HIE occurred in 59 (64.13\%) out of 92 asphyxiated neonates. According to Sarnat and Sarnat clinical HIE staging, 33 (55.93\%) newborns had stage I, 18 $(30.51 \%)$ had stage II and $8(13.56 \%)$ of the newborns had stage III HIE. Renal involvement occurred in 43 (46.7\%) of the total asphyxiated neonates and was the most commonly involved system, next to CNS (64.13\%). Conclusion: In this study, there is a statistically significant association between severity of perinatal asphyxia and severity of HIE. Apgar score at 1 minute is inversely related to the stages of HIE. Though the neonatal factors like male sex, SGA, LGA and perinatal factors like MSAF, PROM, maternal anemia, LSCS, instrumental delivery and breech presentation are associated with the outcome of HIE (sequelae/death), there is no statistically significant association.
\end{abstract}

Key words: Asphyxia, Hypoxic ischemic encephalopathy, Sarnat and Sarnat staging

\section{Introduction}

Birth Asphyxia is one of the major causes of early neonatal mortality in India. Among the institutional births, incidence is $5 \%$ and accounts for $23 \%$ of neonatal deaths. Asphyxia is the single most important cause of still-births accounting for $45.1 \%$ of all cases[1]. The incidence of birth asphyxia reported from developing countries varies from 9.4 to 299 per 1000 live births. Although many organ systems can be affected by hypoxia-ischaemia, it is the nervous system that bears the brunt of perinatal asphyxia in the long

Manuscript received: $14^{\text {th }}$ May 2018

Reviewed: $24^{\text {th }}$ May 2018

Author Corrected: $30^{\text {th }}$ May 2018

Accepted for Publication: $4^{\text {th }}$ June 2018 run. Cerebral palsy is the most important long-term outcome of birth asphyxia and may be accompanied by mental retardation, seizure disorder, or other associated neurological or sensory (visual, auditory) disabilities [2]. Improved antenatal care will definitely bring down the incidence of birth asphyxia. Once the cerebral injury has occurred, the management is mainly supportive.

Newer cerebro protective therapies are being tried. The outcome depends on various factors [3]. Since the contribution of birth asphyxia to burden of neuro disability in developing countries is still to be accurately defined, hence the study. So also to assess 
Editorial

the direct relationship between severity of asphyxia and stage of HIEaswellasclinico laboratory profile and immediate outcome.

\section{Aims and Objectives}

The present was undertaken

- To assess the perinatal factors contributing for the development of HIE in asphyxiated babies.

- To correlate the degree of asphyxia with the stage of HIE.

- To assess the clinic laboratory profile and immediate outcome in asphyxiated newborns.

\section{Materials and Methods}

The present study was conducted from September 2015 to August 2017 in NICU ASRAM Medical College, Eluru. 92 newborn babies, who fulfilled the selection criteria for perinatal asphyxia, formed the study group.

Study design: It is a prospective, descriptive clinical study. Inclusioncriteria: Term asphyxiated newborns including in hospital births and out born asphyxiated babies referred to ASRAM within one hour after delivery.

Exclusion criteria: Newborns with Congenital dysmorphism, Congenital neuromuscular diseases, CNS, cardiac, pulmonary congenital malformations, discharged against medical advice/ Not willing to give consent for the study.

The term infants were identified of having had Perinatal Asphyxia when at leastthree of the following criteria are fulfilled $[6,7]$

1. $\mathrm{pH} \leq 7.2$ (whether metabolic or mixed) determined by blood gas analysis within first hour of the birth.

2. Apgar score: $<4$ at one minute and/or $<7$ at five minutes.

3. Requirement of more than one minute of positive pressure ventilation before sustained respiration occurred.

4. Fetal heart rate abnormalities (Fetal bradycardia $<100$ beats/minute or fetal tachycardia $>160$ beats/minute) and/or presence of meconium stained amniotic fluid.

Complete obstetric history was obtained and examination of the babies was performed at the time of admission. The neonatal clinical course was followed up prospectively and data were recorded on predesigned proforma. Informed written parental consent was obtained for all infants before entry in the study, which was approved by the ethical committee.

Neurological Assessment: Detailed neurological examination of the asphyxiated newborns was performed at 12-24 hours intervals for the first six days and thereafter every alternate day until discharge or until death. The stage of encephalopathy was assessed according to Sarnat and Sarnat Clinical staging system [5]. Perinatal asphyxia was graded as moderate or severe based on $\mathrm{pH}$ [4] and/ or Apgarscore. HIE was graded as mild, moderate, severe based on Sarnat and Sarnat clinical stages of HIE [5]. The relationship between severity of perinatal asphyxia and severity of HIE was studied. The involvement of other organ systems was also noted on the basis of the clinical/ laboratory criteria[6].

A. Renal: Anuria/oliguria $(<1 \mathrm{ml} / \mathrm{kg} / \mathrm{hr})$ for 24 hours or more (after a volume challenge test) with azotemia (Blood urea Nitrogen $>20 \mathrm{mg} / \mathrm{dl}$ ) and/or Serum Creatinine $>1.2 \mathrm{mg} / \mathrm{dl}$ for two or more consecutive days. (Blood samples were obtained at approximately 12 hours of age and repeated when necessary).

B. Pulmonary: Need for $\mathrm{FiO}_{2}>0.4$ for at least first 4 hours and/or mechanical ventilation not required for apnea or heart failure.

C. Cardiovascular: Heart murmur and/or ECG abnormalities characteristic of myocardial ischemia and/or echocardio-graphic evaluation of papillary muscle dysfunction, poor contractility (done within 24 hours of birth and repeated as needed) and/or clinical signs of heart failure (tachycardia, tachypnea and hepatomegaly).

D. Gastrointestinal: Repeated bloody gastric residuals and/or repeated vomiting sand/or features suggestive of necrotizing enterocolitis.

Neonates were followed up for 12 weeks and the outcome in the form of persisting neurological abnormality and/or mortality, if any were noted. The data obtained was analyzed by using the following statistical methods.

Statistical Methods [8,9]- Chi square test and 2x2, 2x3 and $3 \times 3$ Fisher Exact test has been used to find the significant association of HIE staging and outcome and other study characteristics. Similarly, similar tests have been used to find the significant association of Neonatal 
Editorial

and Perinatal factors with the presence of HIE and outcome of HIE. Analysis of Variance/ Kruskal Wallis test has been used to find the significance of Apgar score with HIE stage. Statisticals of tware: The
Statistical software namely SPSS 15.0, Stata 8.0, Med Calc 9.0.1 and Systat 11.0 were used for the analysis of the data and Microsoft word and Excel have been used to generate graphs, tables etc.

\section{Results}

Out of 92 asphyxiated new borns, 48 (52.2\%) are males babies and 44 (47.8\%) are female babies. According to Weight for gestational age, $24(26.1 \%)$ are Small for Gestational Age, 60 (65.2\%) are Appropriate for Gestational Age and, 8 $(8.7 \%)$ are Large for Gestational Age.

Distribution of Perinatal factors among the asphyxiated newborns- Among the study group, 51 (55.4\%) neonates, mothers were Primigravida and $41(44.6 \%)$ neonates' mothers were multigravida. $15(16.3 \%)$ of the babies were born to PIH mothers, $3(3.3 \%)$ were born to APH mothers and $16(17.4 \%)$ were born to anemic mothers. PROM was associated with $9(9.8 \%)$ of the asphyxiated babies. There was presence of Meconium Stained Amniotic Fluid (MSAF) in 51 $(55.4 \%)$ of the asphyxiated babies. $84(91.3 \%)$ had vertex presentation and breech presentation occurred in $8(8.7 \%)$. II stage of labor was prolonged in $12(13.0 \%)$, and cord Prolapse was seen in 1 baby $(1.1 \%)$.

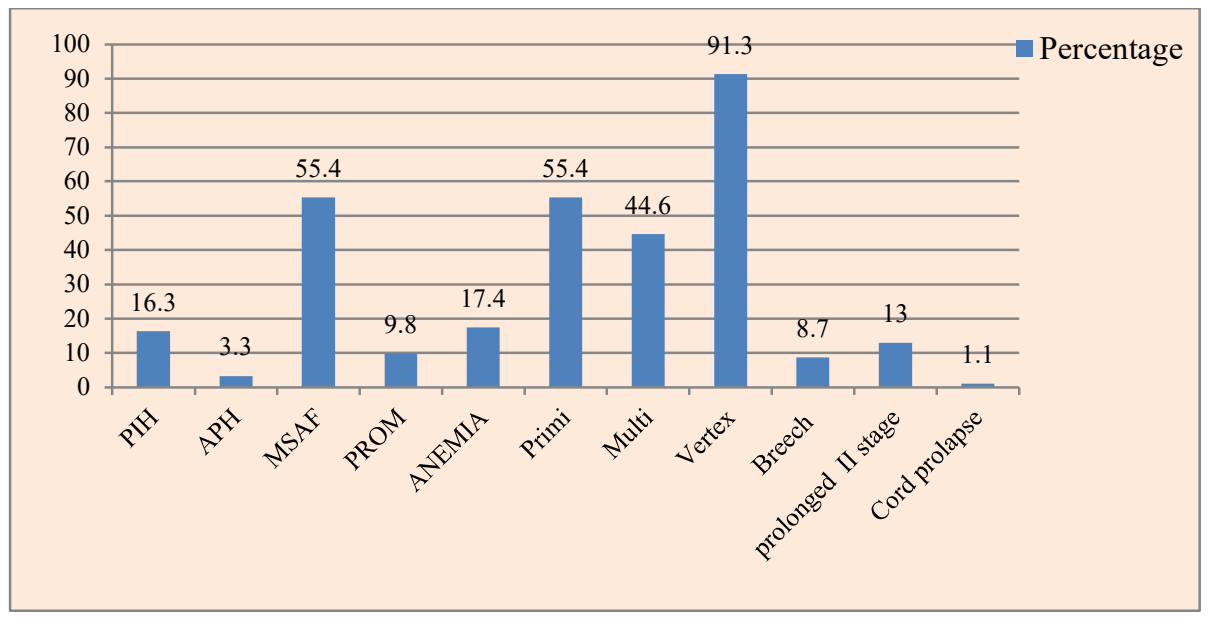

Fig-1: Bar diagram showing perinatal factors among the Asphyxiated Newborns

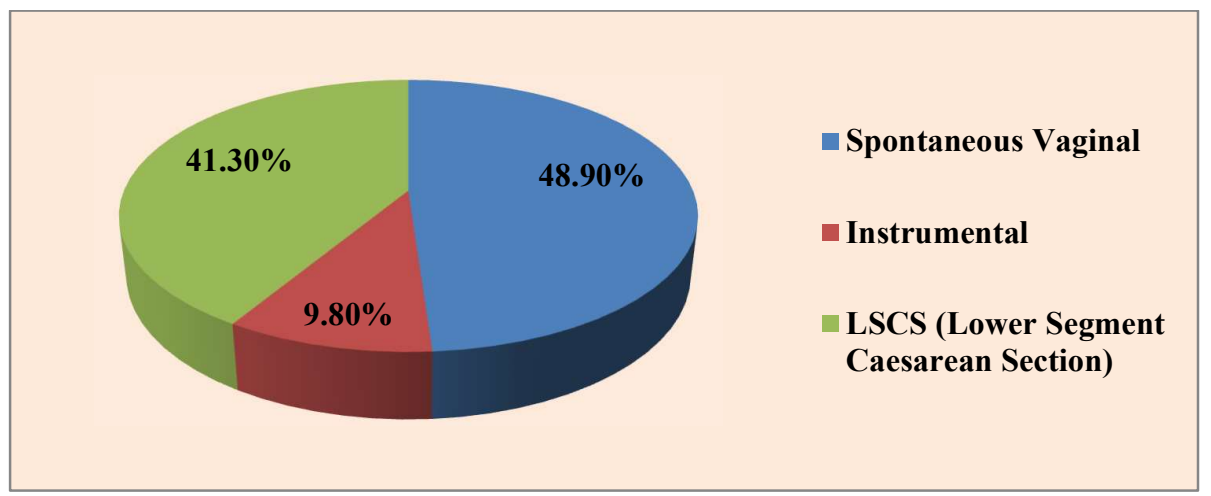

Fig-2: Pie diagram showing distribution of asphyxiated newborns according to mode of delivery

Of the total 92 asphyxiated babies, 45 (48.9\%) were born by spontaneous vaginal delivery, 38 (41.3\%) were born by LSCS and $9(9.8 \%)$ of them by instrumental delivery.

Of the 92 asphyxiated newborns, 59 of them developed HIE accounting for $64.13 \%$, and those without HIE are 33 accounting for $35.87 \%$. Of the 59 newborns who developed HIE, 33 (55.93\%) had stage I encephalopathy, 18 (30.51\%) had stage II and $8(13.56 \%)$ of them had stage III HIE. Of the 59 HIE newborns, 46 (77.9\%) were normal, 7 (11.9\%) of them had persisting neurological abnormality and $6(10.2 \%)$ of them died. 
Editorial

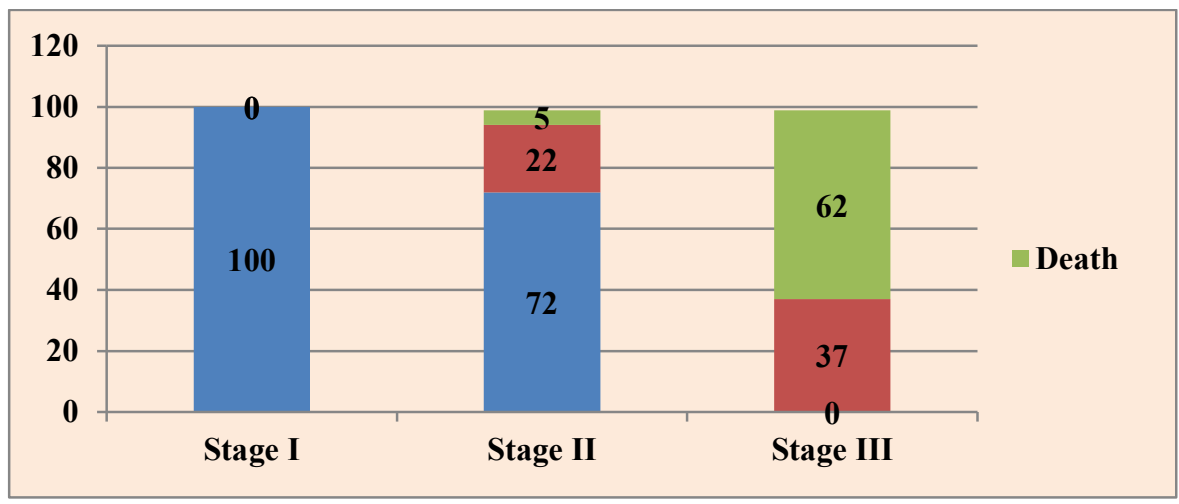

Fig-3: Stacked Bar diagram showing outcome in HIE stages

Among HIE stage I, all the babies that is 33 (100\%) were normal, in HIE Stage II 13 (72.2\%) were normal, 4 (22.2\%) of them had persisting neurological abnormality and 1 (5.6\%) newborn died. In HIE stage III, 3 (37.5\%) had persisting neurological abnormality and 5 (62.5\%) newborns died.

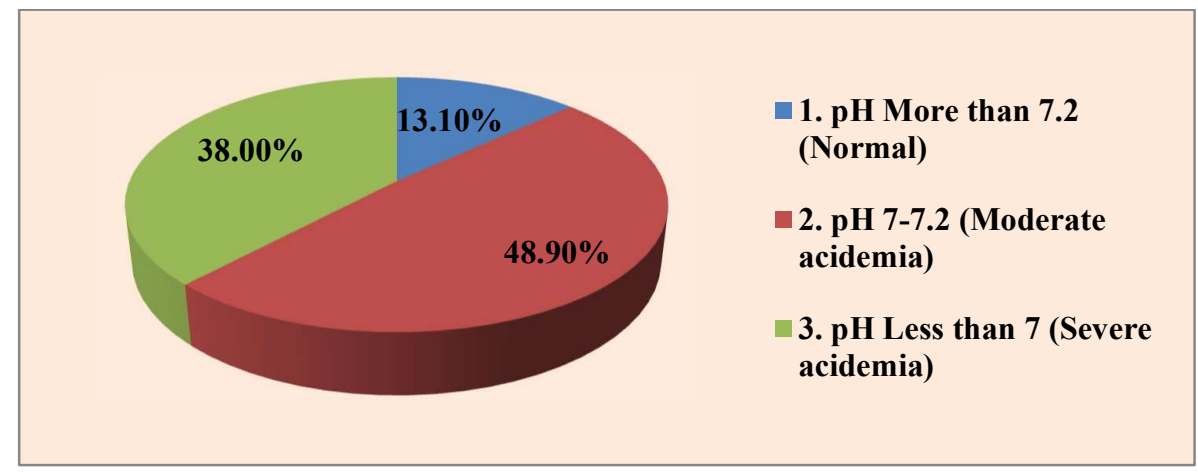

Fig-4: Pie chart showing distribution of arterial blood pH

Of the 92 asphyxiated newborns, 45 (48.9\%) of them had moderate acidemia, $35(38.0 \%)$ newborns had severe acidemia and $12(13.1 \%)$ neonates had normal ph.p value $<0.003 *$ shows that arterial blood ph has significant association with Perinatal asphyxia.

Table -1: Correlation of Apgar score values with HIE stages

\begin{tabular}{|c|c|c|}
\hline \multirow{2}{*}{ HIE stage } & \multicolumn{2}{|c|}{ Apgar score (at 1 minute) } \\
\cline { 2 - 3 } & Range & Median \\
\hline Stage I & $2-5$ & 4.00 \\
\hline Stage II & $1-4$ & 3.00 \\
\hline Stage III & $1-3$ & 2.00 \\
\hline Inference & As the Apgar score decreases the HIE stage increase with $\mathrm{p}<0.001^{* *}$ \\
\hline
\end{tabular}

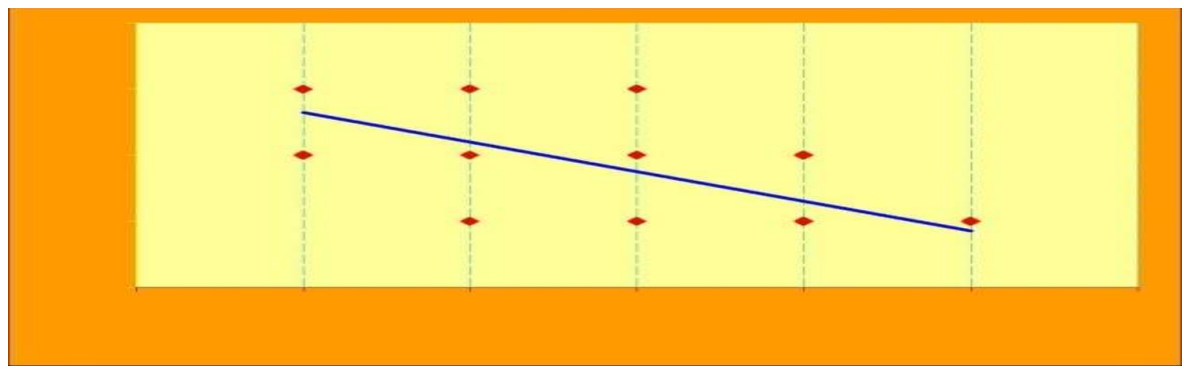

Fig-5: Line diagram showing correlation of Apgar score (1 min) with HIE stages 
Editorial

\section{APGAR SCORE}

The severity of HIE (HIE stages) increases with the decreasing Apgar score values at 1 minute which is statistically significant $(\mathrm{p}<0.001)$.

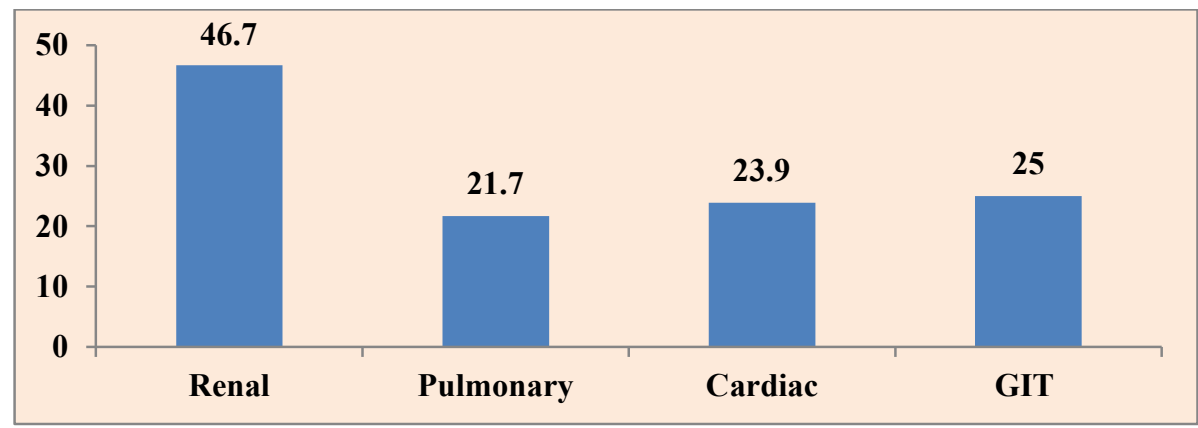

Fig-6: Frequency of organ involvement among the asphyxiated newborns

Out of the 92 asphyxiated newborns, CNS was the most frequently involved organ accounting for $64.13 \%$, followed by kidney in $46.7 \%$. Pulmonary involvement occurred in $21.7 \%$, cardiac involvement was seen in $23.9 \%$ and GIT was involved $25.0 \%$ newborns.

Table-2: Multiple organ involvement among the asphyxiated newborns

\begin{tabular}{|c|c|c|c|}
\hline & Organ involvement & $\begin{array}{c}\text { Number } \\
(\mathbf{n = 9 2})\end{array}$ & Percentage\% \\
\hline Group 0 & No organ involvement & 32 & 34.8 \\
\hline Group 1 & One organ involvement & 10 & 10.9 \\
\hline Group 2 & Two or more organ involvement & 50 & 54.3 \\
\hline
\end{tabular}

Out of the 92 asphyxiated newborns, $50(54.3 \%)$ of them had 2 or more organ involvement. In $10(10.9 \%)$ newborns abnormality was confined to one organ and $32(34.8 \%)$ newborns had no evidence of any organ injury.

Table-3: Multiple organ involvement associated with HIE stages.

\begin{tabular}{|c|c|c|c|c|}
\hline $\begin{array}{c}\text { Organ involvement } \\
\text { (other than CNS) }\end{array}$ & $\begin{array}{c}\text { Stage 1 } \\
(\mathbf{n = 3 3 )}\end{array}$ & $\begin{array}{c}\text { Stage 2 } \\
(\mathbf{n = 1 8})\end{array}$ & $\begin{array}{c}\text { Stage 3 } \\
(\mathbf{n = 8})\end{array}$ & Total \\
\hline No organ involved & $10(30.30)$ & - & - & 10 \\
\hline One organ involved & $18(54.54)$ & $02(11.11)$ & - & 20 \\
\hline Two organs involved & $03(09.09)$ & $07(38.89)$ & - & 10 \\
\hline Three organs involved & $02(06.07)$ & $07(38.89)$ & - & 09 \\
\hline Four organs involved & - & $02(11.11)$ & $08(100)$ & 10 \\
\hline Total & $\mathbf{3 3 ( 1 0 0 )}$ & $\mathbf{1 8 ( 1 0 0 )}$ & $\mathbf{8 ( 1 0 0 )}$ & $\mathbf{5 9}$ \\
\hline
\end{tabular}

Note: Figures in parentheses indicate percentages. Of the HIE stage I, majority of the newborns that is 18 (54.54\%) had abnormality confined to one organ and $10(30.30 \%)$ newborns had no evidence of any organ injury. Among stage II HIE, all of them, that is, $18(100 \%)$ had one or more organ involvement, whereas in stage III HIE, all of them, that is, 8 $(100 \%)$ had involvement of all the other organ systems (four) assessed in the present study.

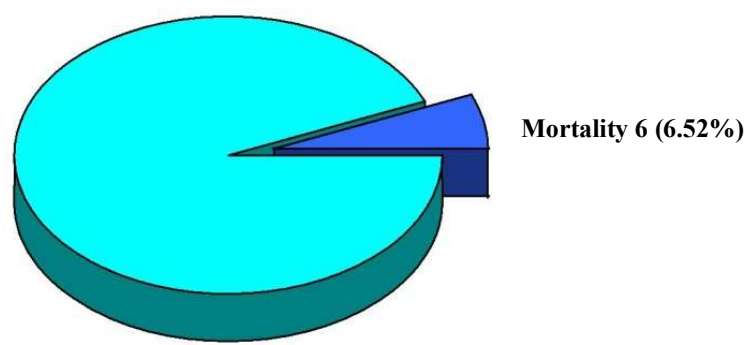

Fig-7: Pie diagram showing mortality among the asphyxiated newborns 
Editorial

Table-4: Association of perinatal factors with HIE.

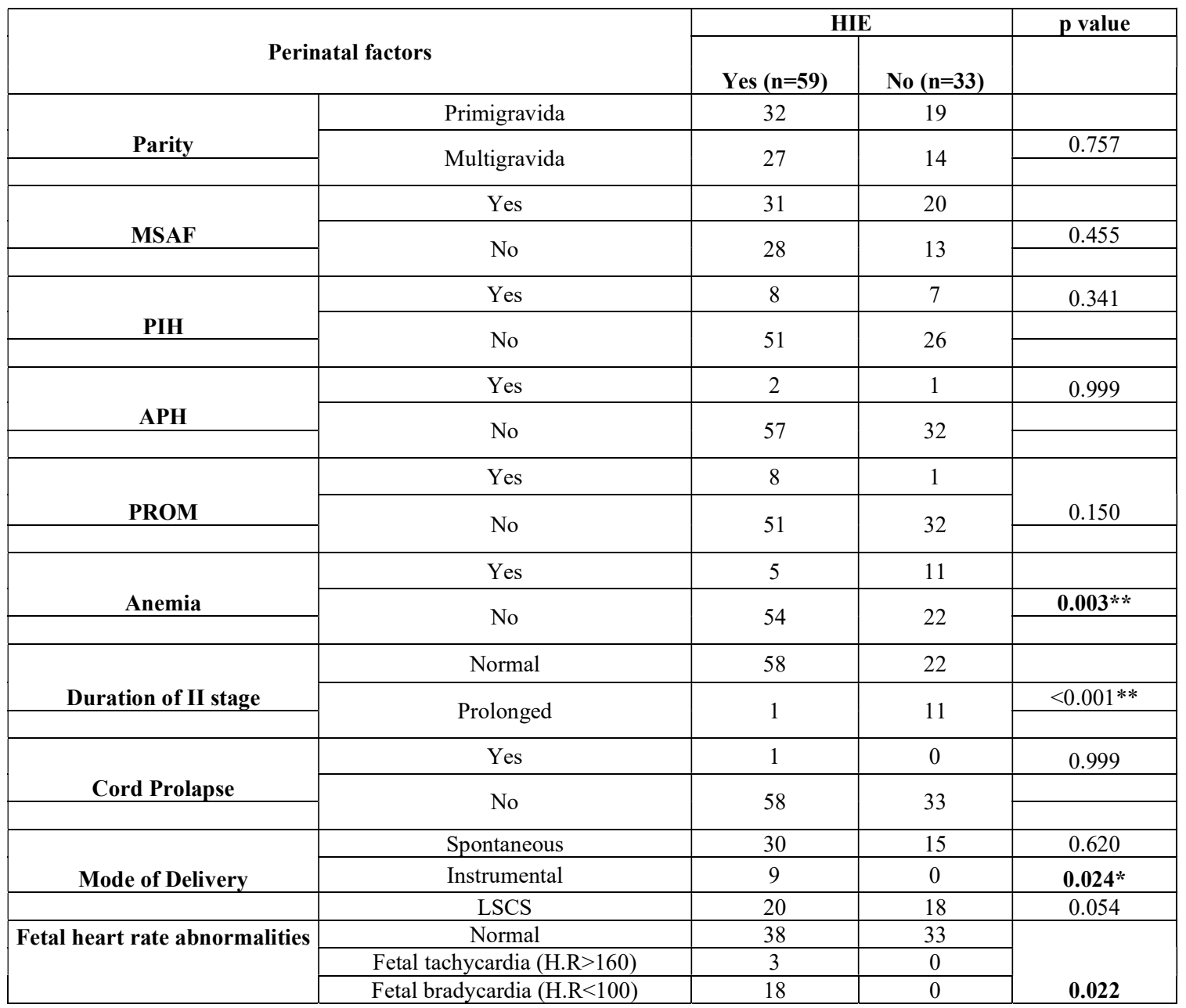

The above table shows that perinatal factors with statistically significant association with the development of HIE are, maternal Anemia, Prolonged $2^{\text {nd }}$ stage of labour, Instrumental delivery and fetal heartrate abnormalities.

Table- 5: Association of Neonatal factors with HIE

\begin{tabular}{|c|c|c|c|c|}
\hline \multicolumn{2}{|c|}{ Neonatal } & \multicolumn{2}{|c|}{ HIE } & \multirow[t]{2}{*}{ p value } \\
\hline & & \multirow{2}{*}{$\begin{array}{c}\text { Yes(no=59) } \\
23\end{array}$} & \multirow{2}{*}{$\begin{array}{c}\mathbf{N o}(\mathbf{n o}=\mathbf{3 3}) \\
15\end{array}$} & \\
\hline \multirow[t]{2}{*}{ Inborn/outborn } & Inborn & & & \multirow[t]{2}{*}{0.545} \\
\hline & Outborn & 36 & 18 & \\
\hline \multirow[t]{2}{*}{ Gender } & Male & 34 & 14 & \multirow[t]{2}{*}{0.161} \\
\hline & Female & 25 & 19 & \\
\hline \multirow{3}{*}{$\begin{array}{c}\text { Weight for } \\
\text { gestational age }\end{array}$} & SGA & 17 & 7 & 0.426 \\
\hline & AGA & 38 & 22 & 0.827 \\
\hline & LGA & 04 & 4 & 0.451 \\
\hline \multirow[t]{2}{*}{ Presentation } & Vertex & 55 & 29 & \multirow[t]{2}{*}{0.451} \\
\hline & Breech & 4 & 4 & \\
\hline \multirow{2}{*}{$\begin{array}{c}\text { Gestational } \\
\text { Maturity }\end{array}$} & Term & 56 & 33 & \multirow[t]{2}{*}{0.550} \\
\hline & Post term & 3 & 0 & \\
\hline \multirow{2}{*}{$\begin{array}{l}\text { (APGAR SCORE) } \\
\text { Perinatal asphyxia }\end{array}$} & Mild /Moderate & 51 & 33 & \multirow[t]{2}{*}{$<0.001 *$} \\
\hline & Severe & 8 & 0 & \\
\hline \multirow[t]{3}{*}{$\mathrm{pH}$} & $>7.2$ (normal) & 2 & 20 & \multirow[t]{3}{*}{$<0.003$} \\
\hline & 7-7.2 (moderate acidemia) & 45 & 13 & \\
\hline & $<7$ (severe acidemia) & 12 & 0 & \\
\hline
\end{tabular}


Editorial

The above table shows that none of the neonatal factors have statistically significant association with the development of HIE except for APGAR scores and $\mathrm{pH}$ which have significant association with development of HIE.

\section{Discussion}

This study was conducted as an attempt to evaluate the development of encephalopathy in term asphyxiated neonates, to correlate the severity of asphyxial insult to the severity of HIE and to assess the immediate outcome.According to the presence of primary signs of acute neonatal encephalopathy, the CNS was the most frequently involved organ in the present study. HIE occurred in $59(64.13 \%)$ out of 92 asphyxiated neonates.

Table-6: The proportion of asphyxiated newborns developing HIE in different studies is shown by the table below:

\begin{tabular}{|c|c|c|}
\hline S No. & Study & HIE followingperinatal hypoxia \\
\hline 1 & Present study & $\mathbf{6 4 . 1 3 \%}$ \\
\hline 2 & Martin Ancel et al[6] & $72 \%$ \\
\hline 3 & Gonzalez de DJ, Moya M[10] & $25.6 \%$ \\
\hline 4 & Thornberg et al[11] & $33.03 \%$ \\
\hline
\end{tabular}

The difference in the proportion of HIE following perinatal asphyxia were probably due to the lack of generally accepted definition of asphyxia. The inclusion criteria for birth asphyxia are different in different studies. It is possible that incidence of neonatal encephalopathy also depends on the sample of the newborns studied (with respect to gestational age) and the criteria used to define neonatal encephalopathy. This may be the probable reason for the variations in the occurrence of post-asphyxial HIE in different studies.

In the present study, HIE newborns were categorized into 3 different clinical stages according to Sarnat and Sarnat staging. 33 (55.93\%) newborns had stage I, 18 (30.51\%) had stage II and 8 (13.56\%) had stage III encephalopathy.

Table-7: In other studies, the proportion of HIE neonates in different stages are as follows:

\begin{tabular}{|c|c|c|c|c|}
\hline S No. & Study & HIE Stage I & HIE Stage II & HIE Stage III \\
\hline 1 & Present study & $55.93 \%$ & $30.51 \%$ & $13.56 \%$ \\
\hline 2 & Martin Ancel et al[6] & $57.7 \%$ & $28.8 \%$ & $13.5 \%$ \\
\hline 3 & Gonzalez de DJ, Moya M [10] & $75 \%$ & $12.5 \%$ & $12.5 \%$ \\
\hline 4 & Robertson C, Finer N [12] & $39.5 \%$ & $56.3 \%$ & $4.2 \%$ \\
\hline 5 & Funayama CA [13]et al & $45.7 \%$ & $42.5 \%$ & $11.8 \%$ \\
\hline
\end{tabular}

In the present study, the outcome of HIE neonates was as follows: Of the 59 HIE neonates 46 (77.9\%) were normal, 7 $(11.9 \%)$ of them had persisting neurological abnormalities and $6(10.2 \%)$ newborns died.

In the study done by Peliowski and Finer [14], overall risk of death in HIE neonates was $12.5 \%$, and $14.3 \%$ for neurological sequelae which is higher than that of present study.Among the HIE stages, all the 33 (100\%) newborns in stage I, were normal. In stage II, 13 (72.2\%) newborns were normal, 4 (22.2\%) had persisting neurological abnormality and $1(5.6 \%)$ newborn died. In stage III, $3(37.5 \%)$ newborns had persisting neurological abnormality and $5(62.5 \%)$ died. HIE stage I was significantly associated $(\mathrm{p}<0.001)$ with normal outcome and HIE stage III was significantly $(\mathrm{p}<0.001)$ associated with death.

Table-8: The outcome of HIE neonates in the various studies is as follows:

\begin{tabular}{|c|c|c|c|}
\hline Present study & HIE Stage I & HIE Stage II & HIE Stage III \\
\hline Death & ---- & $1(5.6 \%)$ & $5(62.5 \%)$ \\
\hline Persistingneurological abnormality & ---- & $4(22.2 \%)$ & $3(37.5 \%)$ \\
\hline
\end{tabular}

In the present study, the distribution of arterial blood $\mathrm{pH}$ (done within one hour of birth) among the study group is as follows: mean $\mathrm{pH}$ was 7.06 \pm 0.09 (Range 6.92-7.25). 12 neonates (13.1\%) had $\mathrm{pH}>7.2,45$ (48.9\%) had $\mathrm{pH} 7-7.2$ (moderate acidemia), 35 (38.0\%) had $\mathrm{pH}<7$ (severe acidemia). 
Editorial

In the present study, 1 minute Apgar score was $\leq 3$ in 33 neonates. 5 minute Apgarscore was $\geq 7$ in 47, 4-6 in 42, $\leq 3$ in 3 neonates. In the present study, there was a statistically significant $(\mathrm{p}<0.001)$ association between severity of perinatal asphyxia and severity of HIE. As the Apgar score at 1 minute decreases the severity of HIE increases. Similarly in the study done by Gonzalez de DJ and Moya M [23], there was a statistically significant $(\mathrm{p}<0.001)$ association between severity of perinatal asphyxia and evidence of HIE. In the study done by Martin Anceletal [6], Apgar score (at 1 and 5 minutes) was the only perinatal factor significantly related to the number of organs affected and to the severity of organ involvement. Other studiesalso have found the relationship between the Apgar score and short-term morbidity after perinatal asphyxia $[15,16]$. Although, this is an unreliable predictor of permanent neurological deficit [17] Low Apgar scores may be the result of factors other than perinatal asphyxia and caution is needed in the interpretation of an individual Apgar score; other data are necessary to establish the diagnosis of perinatal asphyxia.

According to the study done by Murayet. al [18] fetal heart rate pattern had no significant association with development of HIE, which is not in consistency with the present study.

In the present study, involvement of other organs was studied. Renal involvement occurred in 43 (46.7\%) of the total asphyxiated neonates and was the most commonly involved organ, next only to HIE (64.13\%). Pulmonary involvement occurred in $20(21.7 \%)$, cardiac in $22(23.9 \%)$ and involvement of GIT was seen in $23(25.0 \%)$. In the study done by Martin Anceletal [6], renal involvement occurred in $42 \%$, which is slightly lower than the present study. Pulmonary involvement occurred in 26\%, which is slightly higher than present study. Cardiac involvement occurred in 29\% and GIT in $29 \%$, both of which are higher than present study.

Table-9: The frequency of organ system involvement following perinatal asphyxia in different studies is shown in the table below:

\begin{tabular}{|c|c|c|c|c|c|}
\hline S No & Study & Renal & Pulmonary & CVS & GIT \\
\hline $\mathbf{1}$ & Present study & $\mathbf{4 6 . 7 \%}$ & $\mathbf{2 1 . 7 \%}$ & $\mathbf{2 3 . 9 \%}$ & $\mathbf{2 5 . 0 \%}$ \\
\hline $\mathbf{2}$ & Martin Ancel et al $[6]$ & $42 \%$ & $26 \%$ & $29 \%$ & $29 \%$ \\
\hline $\mathbf{3}$ & Perlman JM et al[17] & $50 \%$ & $23 \%$ & $25 \%$ & - \\
\hline $\mathbf{4}$ & Shah P et al[20] & $70 \%$ & $86 \%$ & $62 \%$ & - \\
\hline
\end{tabular}

The organ involvement in the present study is comparable with Martin Ancel et al and Perlman JM et al studies. The variability in the occurrence of organ dysfunction in Shah $\mathrm{P}$ et al study compared to the present study could be due to difference in the inclusion criteria of the study group, difference in the definition of each organ/system dysfunction and variability in timing of blood sample and other investigations done during the evaluation of organ dysfunction.

In the present study, multiple organ involvement was studied by dividing total 92 asphyxiated neonates into 3 groups.

Group 0: were the neonates with no evidence of any organ dysfunction-32 (34.8\%).

Group 1: were the $10(10.9 \%)$ neonates with one organ involvement.

Group 2: were the $50(54.3 \%)$ neonates with 2 or more organ involvement.

In the present study involvement of one or more organ occurred in $66.3 \%$ of neonates.

Table-10: Multiple organ involvement in asphyxiated neonates in various studies is as follows:

\begin{tabular}{|c|c|c|c|}
\hline & Present study & Martin Anceletal[6] & Perlman JM et al[19] \\
\hline Group 0 & $34.8 \%$ & $18 \%$ & $34 \%$ \\
\hline Group 1 & $10.9 \%$ & $26 \%$ & $23 \%$ \\
\hline Group 2 & $54.3 \%$ & $55 \%$ & $43 \%$ \\
\hline
\end{tabular}

Among 59 HIE neonates, majority that is 20 (33.9\%) had one organ involvement (other than CNS) and the most frequently associated organ was kidney.

Murmu M.C et.al. amongst 64 asphyxiated newborns found kidney as most commonly involved organ.According to this study mortality among asphyxiated newborns was directly related to severity of perinatal asphyxia and presence of oliguria. These findings are similar to the present study in which $46.7 \%$ of asphyxiated newborns are with renal involvement [77]. 
Editorial

Ramesh S. Pattaret. al. [21] observed CVS involvement in 54.3\% which is higher than the present study, in which incidence of CVS involvement is $23.9 \%$. In study done by Ramesh S.Pattar et.al. incidence of CVS involvement was more than the renal involvement, which is not similar to the present study in which renal involvement is more than CVS involvement. Mortality was higher in babies with multi organ dysfunction which increases proportionately with increase in number of organs involved,which is consistent with the present study.

In the study done by Gemmal. Malinet. al[22] low arterial $\mathrm{pH}$ soon after birth in asphyxiated newborns had a strong, consistent and temporal association with neonatal morbidity andmortality which is consistent with the present study which suggests that lowering $\mathrm{pH}$ increases the severity of HIE.

\section{Conclusion}

The results in the present study indicate that perinatal asphyxia is frequently followed by dysfunction of one or more organs during neonatal period. In this study, significant proportion of neonates develop HIE following asphyxia insult.Among the newborns that develop HIE, most of them have stage I encephalopathy.

In this study, among the neonatal and perinatal factors associated with birth asphyxia, Maternal Anemia, prolonged $2^{\text {nd }}$ stage of labour,instrumental delivery and fetal heart abnormalities has moderately significant association with the development of HIE.

In this study, there is a statistically significant association between severity of perinatal asphyxia and severity of HIE. Apgar score at 1 minute is inversely related to the stages of HIE.

In this study, outcome of HIE is closely related to severity of HIE. Stage I HIE is significantly associated with normal outcome and stage III HIE is significantly associated with death. Most of the newborns with stage II HIE have normal outcome, a small proportion of them have sequelae or mortality.

In this study, though the neonatal factors like male sex, SGA, LGA and perinatal factors like MSAF, PROM, LSCS, instrumental delivery and breech presentation are associated with the outcome of HIE (sequelae/death), there is no statistically significant association. Further studies are needed to know the association of these factors with the outcome of HIE.

In this study, most of the stage I HIE newborns have evidence of at least one organ involvement, although some proportion did not show any evidence of organ injury, and all the stage III HIE newborns have all the other (four) organ systems involvement. Future clinical trials of treatment for HIE must carefully evaluate possible side effects on the other organs potentially affected that may not be clinically evident until several hours after the treatment has been instituted.
Prevention of perinatal asphyxia is of utmost importance due to its serious complications. Adequate strengthening of maternal care services, training the primary health care personnel in skills of neonatal resuscitation and care of low birth weight babies can dramatically reduce the incidence of perinatal asphyxia and its outcome and hence reduce the perinatal mortality.

Funding: Nil, Conflict of interest: None initiated, Perission from IRB: Yes

\section{References}

1. Neonatal morbidity and mortality: report of the National Neonatal-Perinatal Database. Indian Pediatr. 1997 Nov;34(11):1039-42

2. Rajeshwar Reddy A, Praveen Kumar. Follow up of Neonates with Perinatal asphyxia. J Neonatol 2004; 18: 22-27.

3. Vishnu Bhat B, Narayanan P. Birth AsphyxiaDefinition and current concepts in management. Indian J PractPediatr 2005; 7: 6-14.

4. Leuthner SR, Das UG. Low Apgar Scores and the definition of birth asphyxia. PediatrClin N Am 2004; 51: 737-745.

5. Cloherty JP, Eichenwald EC, Stark AR. In: Manual of Neonatal care $\left(5^{\text {th }}\right.$ Edn.). Lippincott Williams and Wilkins, Philadelphia. 2004.

6. Martín-Ancel A, García-Alix A, Gayá F, et al. Multiple organ involvement in perinatal asphyxia. J Pediatr. 1995 Nov;127(5):786-93.

7. Chandra S, Ramji S, Thirupuram S. Perinatal asphyxia: multivariate analysis of risk factors in hospital births. Indian Pediatr. 1997 Mar;34(3):206-12.

8. Bernard Rosner (2000),Fundamentals of Biostatistics, $5^{\text {th }}$ Edition, Duxbury. 
Editorial

9. M. Venkataswamy Reddy (2002), Statistics for Mental Health Care Research, NIMHANS publication, INDIA.

10. Gónzalez de Dios J, Moya M. [Perinatal asphyxia, hypoxic-ischemic encephalopathy and neurological sequelae in full-term newborns: an epidemiological study (1)]. Rev Neurol. 1996 Jul;24(131):812-9

11. Thornberg E, Thiringer K, Odeback A, et al.Birth asphyxia: incidence, clinical course and outcome in a Swedish population. Acta Paediatr. 1995 Aug;84 (8): 927-32.

12. Robertson C, Finer N. Term infants with hypoxicischemic encephalopathy: outcome at 3.5 years. Dev Med Child Neurol 1985; 27: 473-484.

13. Funayama CA, de Moura-Ribeiro MV, Gonçalves AL. [Hypoxic- ischemic encephalopathy in newborn infants. Acute period and outcome].Arq Neuropsiquiatr. 1997 Dec;55(4):771-9.

14. Peliowski A, Finer NN. Birth Asphyxia in term infant. In: Sinclair JC, Bracken MB (eds). Effective care of the newborn infant. Oxford University Press, Oxford 1992.

15. Portman RJ, Carter BS, Gaylord MS, et al. Predicting neonatal morbidity after perinatal asphyxia: a scoring system. Am J Obstet Gynecol. 1990 Jan; 62 (1): 174-82.

16. Perlman JM, Risser R. Severe fetal acidemia: neonatal neurologic features and short-term outcome. Pediatr Neurol 1993; 9: 277-282.
17. Freeman JM, Nelson KB. Intrapartum asphyxia and cerebral palsy. Pediatrics. 1988 Aug;82(2):240-9.

18Murray DM, O'Riordan MN, Horgan R, Boylan G, Higgins JR, Ryan CA.Fetal heart rate patterns in neonatal hypoxic-ischemic encephalopathy: relationship with early cerebral activity and neurodevelopmental outcome. Am J Perinatol. 2009 Sep; 26(8):605-12. doi: 10.1055/s-0029-1220774.

19. Perlman JM, Tack ED, Martin T, et al. Acute systemic organ injury in term infants after asphyxia. Am J Dis Child. 1989 May;143(5):617-20.

20. Shah P, Riphagen S, Beyene J, et al. Multiorgan dysfunction in infants with post-asphyxial hypoxic-

ischaemic encephalopathy. Arch Dis Child Fetal Neonatal Ed. 2004 Mar;89(2):F152-5.

21. Ramesh S. Pattar, Anil Raj, Bhuvaneshwari Chandrashekhar Yelamali. Incidence of multiorgan dysfunction in perinatal asphyxia. Int J ContempPediatr. 2015 Nov; 2 (4):428-432. http://dx.doi.org/10. 18203/ 2349 -3291.ijcp20150989

22. Malin GL, Morris RK, Khan KS. Strength of association between umbilical cord $\mathrm{pH}$ and perinatal and long term outcomes: systematic review and metaanalysis. BMJ. 2010 May 13;340:c1471. doi: 10.1136/ bmj.c1471.

23. González de Dios J, Moya M.[Perinatal asphyxia, hypoxic-ischemic encephalopathy and neurological sequelae in full-term newborns. II. Description and interrelation]. Rev Neurol. 1996 Aug;24(132):969-76

\section{How to cite this article?}

U.M. Rao Kuppili, Simhachalam M, Revathi M.S. A study on clinico-laboratory profile of newborns with perinatal asphyxia admitted to tertiary care hospital. Int J Pediatr Res. 2018;5(6):326-335.doi:10.17511/ijpr.2018.i06.05. 